\title{
Diversity of Ralstonia solanacearum Infecting Eggplant in the Philippines
}

\author{
Melanie L. Lewis Ivey, Brian B. McSpadden Gardener, Nenita Opina, and Sally A. Miller
}

First, second, and fourth authors: Department of Plant Pathology, The Ohio State University, Ohio Agricultural Research and Development Center, Wooster 44691; and third author: Institute of Plant Breeding, University of the Philippines Los Baños, College, Laguna 4031, Philippines.

Accepted for publication 4 June 2007.

\begin{abstract}
Lewis Ivey, M. L, McSpadden Gardner, B. B., Opina, N., and Miller, S. A. 2007. Diversity and geographic distribution of Ralstonia solanacearum from eggplant in the Philippines. Phytopathology 97:1467-1475.

The diversity of Ralstonia solanacearum strains isolated from eggplant (Solanum melongena) grown in five provinces of the Philippine island group of Luzon was assessed using a recently described hierarchical system. All strains keyed to race 1, biovar 3 or 4 . Phylotype-specific multiplex polymerase chain reaction (PCR) indicated that, like most other strains of Asian origin, all the strains in our Philippine collection belong to phylotype I. Taxometric and phylogenetic analyses of partial endoglucanase gene sequences of strains from this collection and those previ-

ously deposited into GenBank revealed at least four subgroups among the otherwise monophyletic phylotype I strains. Nucleotide polymorphisms within each subgroup were infrequent and, among the subgroups identified in this study, variation was always $<1.3 \%$, indicating that the large majority of strains could be assigned to a single sequevar. Genomic DNA fingerprinting using enterobacterial repetitive intergenic consensus (ERIC)PCR revealed additional fine-scale genetic variation that was consistent with the endogluconase sequence data. Whole-pattern and band-based analyses of the genomic fingerprint data revealed four and eight distinct genotypes, respectively, within our collection. Eggplant from infested fields in different provinces tended to harbor mixed populations of ERIC genotypes, with the predominant genotype varying by location.
\end{abstract}

Bacterial wilt, caused by the soilborne bacterium Ralstonia solanacearum (synonyms: Pseudomonas solanacearum, Burkholderia solanacearum), is a widespread disease that can affect more than 450 plant species in tropical, subtropical, and warm temperate regions of the world (21). Economically important hosts of this pathogen include tomato, potato, eggplant, pepper, geranium, and banana $(6,21)$. Direct yield losses vary for each crop according to cultivar, climate, soil type, the presence of root knot nematodes, and strain pathogenicity $(12,21,47)$.

$R$. solanacearum is a highly variable species encompassing six biovars based on biochemical properties $(20,22,23)$ and five races based on host range $(7,23,39)$. Using restriction fragment length polymorphism (RFLP) analysis, the species was divided into two major divisions: 'Asiaticum' and 'Americanum,' based on the geographical origin of the strains $(9,10)$. The Americanum division later was split into two groups (subdivisions a and b) to include strains from Indonesia, which were defined using $16 \mathrm{~S}$ 23S rRNA, polygalacturonase, and endoglucanase sequence analysis (16,46). In 2000, Poussier et al. (40) used partial sequencing of the $h r p \mathrm{~B}$ and endoglucanase genes of strains from Africa to describe a third subdivision (subdivision c). Sequence and RFLP analysis of a specific 280-bp polymerase chain reaction (PCR)-amplified fragment in Asian strains of $R$. solanacearum suggested that the strains present in Asia (Asiaticum division) could be divided into three groups. In 2005, Fegan and Prior (15) proposed a hierarchical classification scheme to reflect the strain diversity within the $R$. solanacearum species complex. Using this classification scheme, strains within the complex can be divided into four taxonomic levels: species, phylotype, sequevar, and

Corresponding author: S. A. Miller; E-mail address: miller.769@osu.edu

doi:10.1094/PHYTO-97-11-1467

(c) 2007 The American Phytopathological Society clone, using PCR with species-specific primers (37), phylotypespecific multiplex PCR (15), endoglucanase gene sequencing (16), and genomic DNA fingerprinting using repetitive extragenic palindromic-PCR (rep-PCR) $(11,48,49)$, respectively. Fegan and Prior (15) defined a phylotype "as a monophyletic cluster of strains revealed by phylogenetic analysis of sequence data" and a sequevar as a collection (two or more strains) of sequences with $<1 \%$ nucleotide differences among the strains. Using this hierarchical scheme, the epidemiological and ecological groupings of $R$. solanacearum strains can be distinguished, thereby allowing pathologists to better predict the biological properties of unknown strains and assist in the development of effective disease management strategies.

Eggplant is one of the most important vegetables consumed in the Philippines and throughout South Asia. Bacterial wilt is ranked as one of the top five diseases of eggplant in Asia (12), making it one of the most serious plant health issues of this crop. Within the Philippines, eggplant production accounts for $\approx 28 \%$ of the total volume of vegetables, which amounts to 179,000 metric tons per year valued at approximately US\$32 million (3). In the Philippines, crop losses consistently reach 30 to $80 \%$ in bacterial wilt-infested fields (36). Because strains within the $R$. solanacearum species complex are so diverse, the development of universal control methods is difficult. Within the Philippines, cultural practices, such as the use of mulch and reduced soil cultivation, have not been successful in reducing bacterial wilt incidence (36). The use of bacterial wilt-susceptible commercial cultivars grafted onto bacterial wilt-resistant rootstocks has been demonstrated to be an effective management tool in both the Philippines and Bangladesh (36). With very few management options available, it is clear that a better understanding of the population structure of this highly diverse pathogen is needed in order to develop pathogen-targeted and, possibly, geographically targeted management practices. The ability to predict the biological, ecological, and epidemiological properties of $R$. solanacearum strains using a meaningful taxo- 
nomic classification system could aid in the development of successful management practices.

The goals of this study were to (i) assess the genetic diversity of the populations of $R$. solanacearum using the hierarchical classification scheme proposed by Fegan and Prior (15) and (ii) characterize their distribution within five provinces in the Philippines. All strains were classified according to biovar and then subjected to genomic fingerprinting using enterobacterial repetitive intergenic consensus (ERIC)-PCR. Representatives from each clonal group were further characterized to phylotype and sequevar.

\section{MATERIALS AND METHODS}

Strain isolation, characterization, and maintenance. Multiple strains of $R$. solanacearum race 1 were recovered from bacterial wilt symptomatic and asymptomatic eggplants from naturally infested fields within five provinces in the island group of Luzon, Philippines: Pangasinan (Ilocos region), Nueva Ecija (Central Luzon region), and Batangas, Quezon, and Laguna (Calabarzon region) (38). The strains were characterized into biovar using Hayward's biochemical test (20). The $\chi^{2}$ test was used to determine whether biotype and province of origin were independent of each other. All strains were stored in nutrient yeast extract broth (NBY) containing $15 \%$ glycerol at $-80^{\circ} \mathrm{C}$.

DNA extraction. $R$. solanacearum strains were grown on 2,3,5-triphenyltetrazolium chloride (TTC) medium (27) for 3 days at room temperature and total genomic DNA was extracted using the Qiagen DNeasy tissue kit (Qiagen Inc., Chatsworth, CA) according to the manufacturer's instructions. DNA was quantified spectrophotometrically at $260 \mathrm{~nm}$ and diluted to $50 \mathrm{ng} / \mu \mathrm{l}$ for subsequent genomic applications.

Genomic fingerprinting and analysis. $R$. solanacearum strains were fingerprinted using the ERIC primers ERIC1R and ERIC2 (11). Two independent amplifications were performed on each strain. ERIC-PCR was performed using the conditions described by Louws et al. (31) in a PTC-100 thermocycler (MJ
Research Inc., Waltham, MA). Amplified PCR products were separated by horizontal gel electrophoresis in $1.5 \%$ agarose gels at $12^{\circ} \mathrm{C}$ in $1 \times$ Tris-acetate-EDTA buffer (TAE; $40 \mathrm{mM}$ Tris, $20 \mathrm{mM}$ acetic acid, and $1 \mathrm{mM}$ EDTA, $\mathrm{pH} 8.3$ ) for $7.5 \mathrm{~h}$ at $50 \mathrm{~V}$. A 100-bp DNA ladder (Invitrogen Life Technologies, Carlsbad, CA) was included in order to normalize the banding pattern of the ERIC-PCR profiles. Gels were stained in dilute ethidium bromide $(2 \mu \mathrm{g} / \mathrm{ml})$, and DNA was visualized under UV light and photographed using the Kodak Electrophoresis Documentation and Analysis System (EDAS) 290 (Eastman Kodak Company, New Haven, CT). Computer-assisted pattern analysis of the genomic fingerprints produced by ERIC-PCR was performed using the GelCompar II (version 2.0) software program as described by Rademaker et al. (43). Analyses were conducted using band- and whole-pattern-based similarities calculated using Pearson's product-moment correlation coefficient. Cluster analysis was performed using the unweighted pair group method with arithmetic means (UPGMA) algorithm. The similarity coefficient used to describe distinct groups of patterns was defined by the 95th percentile near-minimum similarity coefficient of replicate amplifications for identical strains following the procedure described by McSpadden Gardener et al. (35). Association between strain genotype and province of origin was assessed using $\chi^{2}$ goodnessof-fit tests available in Minitab Statistical Software (version 14.0; Minitab, Inc., State College, PA).

Phylotype-specific-multiplex PCR amplification. Phylotypespecific primers (15) generated from the 16S-23S intergenic spacer region of the ribosomal DNA gene were used in combination with a species-specific reverse primer (15) and the speciesspecific primers 759/760 (37). Thirty-five strains representing each band-based genotype for each biovar (biovars 3 and 4) were selected (Table 1). Template DNA for the $R$. solanacearum reference strains GMI1000, K60, WW386, and WW443, representing phylotypes I, II, III, and IV, respectively, was provided by C. Allen (University of Wisconsin-Madison). Each $25-\mu$ l reaction mixture contained $50 \mathrm{ng}$ of template DNA; $0.3 \mu \mathrm{M}$ primers

TABLE 1. Genotypic and phenotypic diversity of representative strains of Ralstonia solanacearum obtained from eggplants grown in the Philippines

\begin{tabular}{|c|c|c|c|c|c|c|}
\hline \multirow[b]{2}{*}{ Province, $n^{\mathrm{a}}$} & \multirow[b]{2}{*}{ Strains $^{b}$} & \multirow[b]{2}{*}{ Biovar } & \multicolumn{2}{|c|}{ ERIC-PCR genotype ${ }^{c}$} & \multirow[b]{2}{*}{ Phylotype } & \multirow[b]{2}{*}{ Endoglucanase subgroup } \\
\hline & & & Whole pattern & Band-based analysis & & \\
\hline \multicolumn{7}{|l|}{ Batangas } \\
\hline 3 & 465,466 & 3 & 3 & E & I & 4 \\
\hline 20 & 437,452 & 4 & 2 & A & I & 1 \\
\hline \multicolumn{7}{|l|}{ Laguna } \\
\hline \multicolumn{7}{|l|}{ Neuva Ecija } \\
\hline 4 & 299,330 & 3 & 1 & $\mathrm{D}$ & I & 1 \\
\hline 1 & 303 & 4 & 1 & $\mathrm{D}$ & I & 1 \\
\hline 1 & 341 & 4 & 1 & $\mathrm{H}$ & I & 1 \\
\hline \multicolumn{7}{|l|}{ Quezon } \\
\hline 1 & 579 & 3 & 1 & B & I & 1 \\
\hline 12 & 552,582 & 3 & 1 & $\mathrm{D}$ & I & 1 \\
\hline 8 & 488,492 & 3 & 4 & G & I & 2 \\
\hline 80 & 123,354 & 4 & 1 & B & I & 1 \\
\hline 1 & 235 & 4 & 1 & D & I & 1 \\
\hline 3 & 196,205 & 4 & 1 & $\mathrm{H}$ & I & 1 \\
\hline 2 & 81,129 & 4 & 1 & I & I & 1 \\
\hline
\end{tabular}

a Number $(n)$ of isolates for each genotype for each province is shown.

${ }^{\mathrm{b}}$ Representative strains. At least one strain representing each enterobacterial repetitive intergenic consensus band-based genotype and biovar combination obtained from each province were selected for further genotypic characterization. Strain 29 is not listed because it did not produce a phylotype-specific amplicon or the expected $\approx 850$-bp amplicon when PCR amplified with the EndoF and EndoR-endoglucanase primers.

${ }^{c}$ Enterobacterial repetitive intergenic consensus polymerase chain reaction (ERIC-PCR). 
Nmult21:1F, Nmult21:2F, and Nmult22:InF; $0.7 \mu \mathrm{M}$ primer Nmult23:AF; $0.2 \mu \mathrm{M}$ primers 759 and $760 ; 0.4 \mu \mathrm{M}$ primer Nmult22:RR; $12.5 \mu \mathrm{l}$ of GoTaq Green Master Mix (GoTaq DNA polymerase at 100 units $/ \mathrm{ml}, 400 \mu \mathrm{M} \mathrm{dNTP}$, and $3 \mathrm{mM} \mathrm{MgCl}_{2}$ ) (Promega Corporation, Madison, WI); and $6.4 \mu \mathrm{l}$ of sterile milliQ water. PCR was performed in a PTC-100 thermocycler (MJ Research Inc.) using the following program: $5 \mathrm{~min}$ at $96^{\circ} \mathrm{C} ; 30$ cycles of $15 \mathrm{~s}$ at $94^{\circ} \mathrm{C}, 30 \mathrm{~s}$ at $59^{\circ} \mathrm{C}$, and $30 \mathrm{~s}$ at $72^{\circ} \mathrm{C}$; and then a 10 -min final extension at $72^{\circ} \mathrm{C}$. PCR products $(10 \mu \mathrm{l})$ were separated by horizontal gel electrophoresis in $1.5 \%$ agarose in $0.5 \times$ Tris-borate EDTA (TBE) buffer at $50 \mathrm{~V}$ for $4 \mathrm{~h}$. Gels were stained and DNA visualized as described above.

Endoglucanase gene PCR amplification. The endoglucanase gene was amplified from the 35 selected $R$. solanacearum strains described above using the primers EndoF (5'-ATGCATGCCGCTGGTCGCCGC-3') and EndoR (5'-GCGTTGCCCGGCACGAACACC-3') (16). Each 25- $\mu$ l reaction mixture contained $50 \mathrm{ng}$ of template DNA, $0.5 \mu \mathrm{M}$ primer, $12.5 \mu \mathrm{l}$ of GoTaq Green Master Mix (GoTaq DNA polymerase at 100 units $/ \mathrm{ml}, 400 \mu \mathrm{M} \mathrm{dNTP}$, and $3 \mathrm{mM} \mathrm{MgCl}_{2}$ ) (Promega Corporation), and $10 \mu \mathrm{l}$ of sterile milliQ water. PCR was performed in a PTC-100 thermocycler (MJ Research Inc.) using the following program: $5 \mathrm{~min}$ at $95^{\circ} \mathrm{C} ; 30$ cycles of $1 \mathrm{~min}$ at $95^{\circ} \mathrm{C}, 1 \mathrm{~min}$ at $70^{\circ} \mathrm{C}$, and $2 \mathrm{~min}$ at $72^{\circ} \mathrm{C}$; and then a 10 -min final extension at $72^{\circ} \mathrm{C}$. PCR products $(2.5 \mu \mathrm{l})$ were separated by horizontal gel electrophoresis in $1.5 \%$ agarose in $0.5 \times \mathrm{TBE}$ buffer at $100 \mathrm{~V}$ for $70 \mathrm{~min}$. Gels were stained and DNA visualized as described above.

Endoglucanase gene sequencing and analysis. The endonuclease gene-containing amplicons were purified using QIAquick PCR purification kits (Qiagen Inc.) according to the manufacturer's instructions. Direct sequencing of the purified amplification products was performed at the Plant-Microbe Genomics Facility, The Ohio State University, Columbus using an automated 3730 DNA Analyzer (Applied Biosystems, Inc.) with a two-step cycle sequencing program and a dGTP modification kit. Base calling and sequence quality were determined using Mac PhredMac Phrap software $(13,14)$. The software Sequencher (Sequencher 3.0; Gene Codes Corporation, Ann Arbor, MI) was used to edit, trim, and generate high quality sequence data. Trim criteria were set to trim no more than $25 \%$ and, until the last 15 bases, contained less than three bases with confidences $<20$. Base call disagreements or ambiguities in the final sequences were edited by eye. Sequences were deposited into GenBank with the following accession numbers: EF192941 (123), EF192942 (205), EF192943 (129), EF192944 (196), EF192945 (235), EF192946 (299), EF192947 (354), EF192948 (357), EF192949 (437), EF192950 (456), EF192951 (465), EF192952 (466), EF192953 (468), EF192954 (488), EF192955 (492), EF192956 (523), EF192957 (551), EF192958 (682), EF192959 (705), EF192960 (81), EF192961 (15), EF192962 (330), EF192963 (359), EF192964 (360), EF192965 (552), EF192966 (580), EF192967 (582), EF192972 (303), EF192973 (341), EF192974 (452), EF192975 (485), EF192976 (579), EF192977 (679), EF192978 (533), EF192968 (GMI 1000), EF192969 (WW443), EF192970 (K60), and EF192971 (WW386).

GenBank, EMBL, DDBJ, and PDB databases were searched for sequence similarities using Gapped BLAST and PSI-BLAST programs (4). The following 21 reference sequences were selected and used in the analysis: AY465012 (MAFF211490) and AY465013 (MAFF211493), both isolated from Zingiber mioga; AY464997 (MAF211479), AY465009 (Ps631), AF295254 (UW151), AY465010 (Z8b), AY464994 (MAFF211475), AY464995 (MAFF211476), R277 (AY465011), and AY464998 (MAFF211471), all isolated from Z. officinale; AF295250 (MAFF211266) and AF295253 (NCPPB3190), isolated from Solanum lycopersicum; AY464985 (E152), AY464981 (WP266) and AF295252 (JT523), isolated from Solanum tuberosum; AY465008 (MAFF211281) and AY464986 (E186) isolated from
S. melongena; and AY465015 (1446), AY464996 (U154), AY464987 (P67), and AF295255 (R292), isolated from Curcuma sp., Nicotiana tabacum, Capsicum annuum, and Morus alba, respectively. All reference sequences were from stains reported to be in phylotype I. Sequence alignments were performed and similarity values were calculated with the ClustalW algorithm in Mac Vector (Mac Vector 6.1; Oxford Molecular Ltd., Beaverton, OR) using default settings. Phylogenetic and taxometric analyses were performed using the software MEGA 3.1 (29) with the neighbor-joining and UPGMA algorithms, respectively. A similarity matrix was calculated using MEGA 3.1 with default settings to determine the average nucleotide differences between and within subgroups within phylotype I. Nucleotide differences between phylotype I strains and the reference strain of each phylotype I, II, and III also were calculated.

\section{RESULTS}

Biovar determination. In all, 179 isolates were collected from five provinces within the island group of Luzon, Philippines. All isolates were classified as race 1 based on the host (eggplant) and as biovar $3(29.4 \%)$ or $4(70.6 \%)$ based on their biochemical profiles (data not shown). Within each province there was one predominant biovar. Biovar 4 strains were predominant in the provinces of Pangasinan (86\%), Batangas (67\%), and Quezon (59\%), while biovar 3 strains predominated in Nueva Ecija (67\%) and Laguna (100\%). A summary of these data and the genotypic data that follow are provided in Table 1.

Genomic fingerprinting of strains. All 179 strains were characterized using ERIC-PCR. Amplification products yielded fingerprint patterns of at least eight fragments ranging in size from 300 to $1,500 \mathrm{bp}$. Among the 179 strains, eight distinct genomic fingerprint patterns (genotypes) were identified using band-based analyses (A to E and G to I). Strains initially grouped into genotype $\mathrm{F}$ were regrouped into genotype $\mathrm{B}$ after the $\mathrm{F}$ genotype could not be reproduced after two independent amplifications and analyses. However, whole-pattern analyses (i.e., those using densitometric curve data of the whole patterns) revealed just four distinct genotypes (Fig. 1). The largest genotypic group generated using whole-pattern cluster analysis, defined as group 1, was split into four distinct clusters (D, I, B, and H) by bandbased analysis. The group 2 genotype was split into two distinct clusters (A and $\mathrm{C}$ ) when band-based analysis was used. The genotypic groups 3 and 4 were identical to the band-based groups $\mathrm{E}$ and $\mathrm{G}$, respectively, and were more rare, representing just three and nine strains, respectively, in our collection.

One predominant band-based genotype was found in each province except Quezon (Table 2). All but 1 of the 32 Quezon and 12 Laguna strains fell into the same whole-pattern cluster (group 1 ), which contained $>79 \%$ of all strains. Group 1 strains predominated in all provinces except Batangas, in which clonal group 2 strains made up $87 \%$ of the total strains recovered. $R$. solanacearum strains characterized as belonging to biovar 3 and biovar 4 were grouped into six (B, C, D, E, G, and I) and five (A, B, D, H, and I) genotypes, respectively. Biovar 4 strains were relatively homogenous, with 98 of the 127 strains $(77.2 \%)$ belonging to the $B$ genotype (band-based analysis). Based on the incidence data (Table 2$)$, there was a significant association $(P<0.01)$ between strain genotype and province of origin for both the band-based and whole-pattern analyses. Specifically, the B genotype predominated in samples from Pangasinan, whereas the A genotype predominated in those taken from Batangas. The D genotype appeared to occur more frequently in samples taken from Laguna, Quezon, and, perhaps, Nueva Ecija.

Phylotyping of strains. Of the 35 representative $R$. solanacearum strains tested, 34 generated the expected 280-bp $R$. solanacearum species-complex-specific amplicon and a 150-bp phylotype-I-specific amplicon. Strain 29 generated the 280-bp 
$R$. solanacearum species-complex-specific amplicon but did not produce any phylotype-specific amplicon.

Characterization of endogluconase sequences. A near fulllength portion of the endoglucanase gene $(\approx 850$ nucleotides [nt]) was amplified using the EndoF/R primers from 34 of the 35 representative $R$. solanacearum strains and sequenced using the EndoF primer. No PCR amplicon was produced from $R$. solanacearum strain 29 using these primers. Nucleotide sequences from these 34 representative strains were obtained and aligned with 24 additional endoglucanase sequences (i.e., 21 phylotype I and one each of phylotypes II, III, and IV) previously deposited in GenBank, EMBL, DDBJ, and PDB databases. BLAST sequence comparisons indicated that the $643 \mathrm{nt}$ portion of the gene (trimmed from $850 \mathrm{nt}$ ) analyzed was predicted to encode 213 amino acids starting in the third reading frame.

As expected, phylotype II and III were most distinct, differing from phylotype I sequences by an average of 53.8 and $42.2 \mathrm{nt}$, or 23.1 and 18.0 amino acids, respectively. The phylotype IV sequences differed by only $36.1 \mathrm{nt}$ and 15.4 amino acids, on average. Alignment of the sequences obtained from phylotype I strains $(n=56)$ revealed $20(3.1 \%)$ variable sites, of which 14 (2.2\%) were phylogenetically informative. Of the 213 corre- sponding amino acids, only eight $(3.8 \%)$ were variable and, of those, only four (1.9\%) phylogenetically informative.

Phylogenetic and taxometric trees were generated using the neighbor-joining and UPGMA algorithm, respectively. Despite different mathematical underpinnings, both analyses produced dendrograms that separated the endoglucanase sequences from the four previously defined phylotypes into distinct clades. Sequences from the eggplant-derived strains occurred in a monophyletic cluster with the phylotype I reference sequences. Within phylotype I, four distinct subgroups with high bootstrap values (i.e., $\geq 75 \%$ ) were identified by phylogenetic analyses (Fig. 2). The other six sequences represented distinct haplotypes, but their relationship to the other four subgroups is ambiguous, as indicated by lower bootstrap support for the branches shown in the two dendrograms. Although the taxometric analysis of the nucleotide sequences divided phylotype I into the same four subgroups (Fig. 3), the bootstrap support for these subgroups was somewhat higher than for those generated by phylogenetic analysis, indicating that some of the polymorphisms that led to splitting in the phylogenetic tree (neighbor joining tree) were not always phylogenetically informative. Subgroups 1,2, and 4 contained strains from this study, with the majority $(87.8 \%)$ falling into subgroup 1.
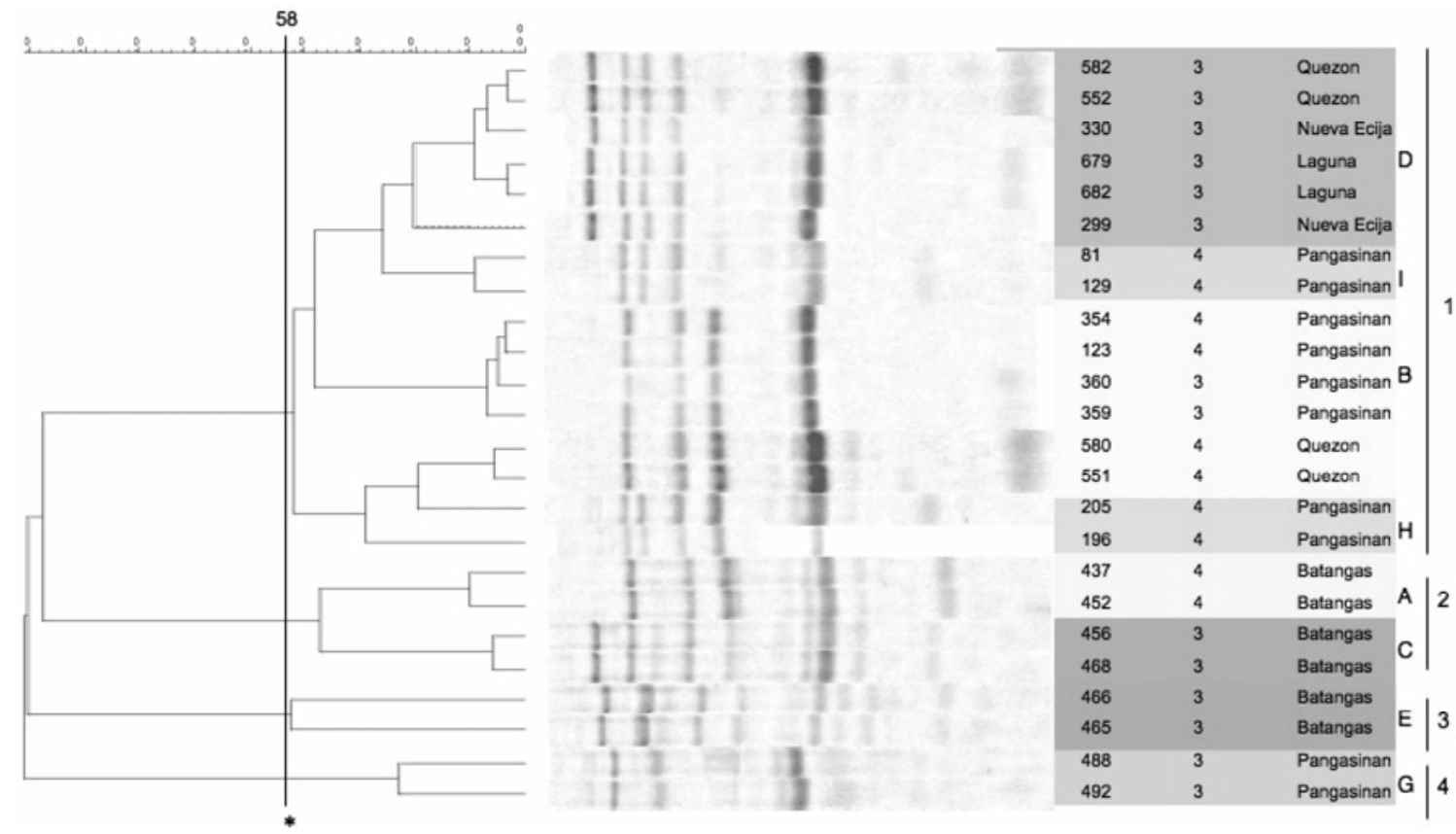

Fig. 1. Cluster analysis of genomic fingerprint patterns of Ralstonia solanacearum strains generated by enterobacterial repetitive intergenic consensus polymerase chain reaction. Patterns representing at least two strains of each biovar obtained from each province are shown. Using GelCompar II (version 2.0), the unweighted pair group method with arithmetic means algorithm was applied to the similarity matrix generated using Pearson's correlation coefficient applied to the whole patterns. The minimum similarity coefficient of all replicated samples $\left(^{*}\right)$ was used to define distinct groups, which are labeled numerically. Distinct groups of band-based genotypes are labeled alphabetically and highlighted in different shades of gray.

TABLE 2. Occurrence of enterobacterial repetitive intergenic consensus (ERIC)-PCR genotypes of race 1 Ralstonia solanacearum strains isolated from eggplants grown in five different provinces of the Philippines

\begin{tabular}{|c|c|c|c|c|c|c|c|c|c|}
\hline \multirow[b]{3}{*}{ Province } & \multicolumn{9}{|c|}{ ERIC-PCR genotype ${ }^{a}$} \\
\hline & \multicolumn{4}{|c|}{1} & \multicolumn{2}{|c|}{2} & \multirow{2}{*}{$\frac{3}{E}$} & \multirow{2}{*}{$\begin{array}{c}4 \\
G\end{array}$} & \multirow[b]{2}{*}{$n^{\mathrm{t}}$} \\
\hline & $\mathrm{B}$ & $\mathrm{D}$ & $\mathrm{H}$ & I & A & $\mathrm{C}$ & & & \\
\hline Quezon & 19 & 12 & 0 & 0 & 1 & 0 & 0 & 0 & 32 \\
\hline Batangas & 1 & 0 & 0 & 0 & 20 & 6 & 3 & 0 & 30 \\
\hline Laguna & 0 & 11 & 0 & 0 & 0 & 0 & 0 & 1 & 12 \\
\hline Nueva Ecija & 0 & 5 & 1 & 0 & 0 & 0 & 0 & 0 & 6 \\
\hline
\end{tabular}

${ }^{a}$ Groupings based on whole-pattern-based analyses are numbered 1 to 4, and groupings based on band-based analyses are labeled A to E and G to I. Group F was not reproducible and therefore dropped from the final analysis.

$\mathrm{b}$ Total number $(n)$ of strains obtained from each location. 
The A, B, C, D, H, and I band-based genotypes and whole-pattern genotypes 1 and 2 were represented in this subgroup. Only the $G$ band-based genotype (whole-pattern genotype 4) was in subgroup 2, whereas subgroup 4 contained only the E band-based genotype (whole-pattern genotype 3). Strains within subgroup 3 originated from three different ginger and mioga species in Thailand (1446) and Japan (MAFF211479, MAFF211490, and MAFF211493) and had an average of $0.5 \mathrm{nt}$ differences among the strains. Strains within subgroup 1 had an average of $0.4 \mathrm{nt}$ differences, but none of the nucleotide polymorphisms present in subgroup 1 sequences were associated with the additional clusters of strains resolved by the ERIC-PCR analyses. Sequences within subgroup 2 were identical (0 nucleotide differences), as were those in subgroup 4 (Table 3).

To determine whether multiple sequevars were present in each of the defined subgroups, the number of nucleotide differences was compared between the strains within each subgroup (Table 3 ). In the definition of sequevar proposed by Prior and Fegan
(15), sequences within a sequevar must have $<1 \%$ nucleotide differences and there should be two or more strains sequenced. Therefore, single sequence clusters are not given sequevar status. Comparisons of nucleotide differences between strains in subgroups 1,2 , and 4 (Table 3 ) show that the nucleotide differences in each comparison was $<1 \%(<5.2 \mathrm{nt})$ and, therefore, only one sequevar (sequence variant) was present in our collection. Comparisons of nucleotide differences between strains in subgroup 3 with strains in subgroups 1,2 , and 4 suggest that strains in subgroup 3 may be a different sequevar than those in 1, 2, and 4 (7.8-, 5.8-, and 7.0-nt differences respectively).

\section{DISCUSSION}

Genomic diversity of strains of $R$. solanacearum (race 1, biovars 3 and 4) causing bacterial wilt of eggplant in three regions of the island group of Luzon, the Philippines, was evaluated using the hierarchical classification scheme proposed by Fegan and

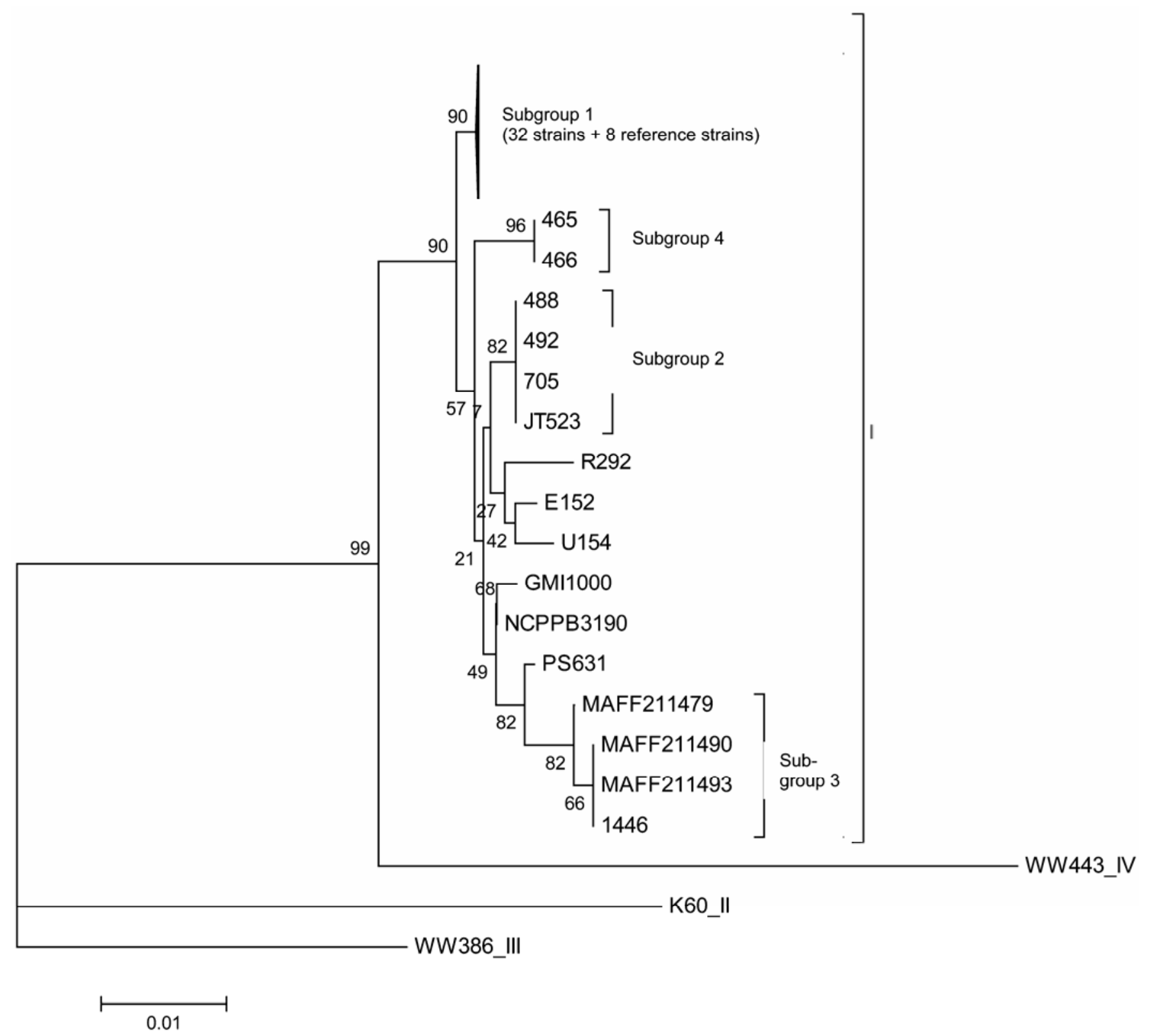

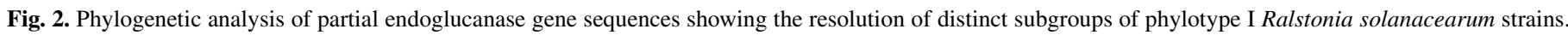

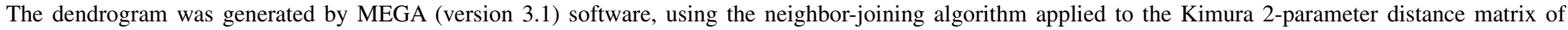

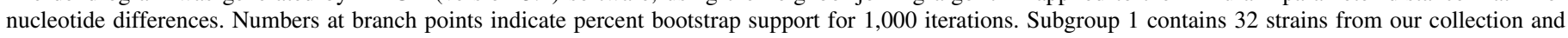
eight reference strains. Roman numerals represent the phylotype. The scale bar represents 1 nucleotide substitution per 100 nucleotides. 
Prior (15). Multiplex PCR with phylotype-specific primers and endoglucanase gene sequences grouped all but one (strain 29) of these strains into phylotype I of the $R$. solanaceraum species complex. Interestingly, no amplicon was produced by PCR for strain 29 using the phylotype-specific primers or the endoglucanase-specific primers, suggesting that this strain may be phylogenetically distinct from the other Philippine strains isolated in this study. Fegan and Prior (15) also found that one of their strains of $R$. solanacearum (ACH0732) isolated from tomato in Australia did not produce a phylotype-specific amplicon but did produce a product with the endoglucanse gene primers. Further characterization of these strains may be warranted. Within the $R$. solanaceraum species complex, strains of biovars 3, 4, and 5 from Asia consistently have fallen into one monophyletic cluster based on PCR-RFLP analysis $(9,10,41)$, 16S rDNA sequences $(16,41$, $46,50)$, the $h r p B$ gene $(40,50)$, the mutS gene (42), and the endoglucanase gene $(40,50)$. Phylotype I strains (both reference strains and strains from this study) were more similar to a phylotype IV reference strain (WW443) than to phylotype II and III reference strains. Studies by Fegan et al. (16), Villa et al. (50), and Fegan and Prior (15) also showed that strains of phylotype I were most similar to the Indonesian strains of phylotype IV when endoglucanse gene sequences were compared. However, comparisons of the $h r p B$ and $m u t S$ genes showed that strains of phylotype I were more closely related to African strains of phylotype III $(15,50)$.

Phylogenetic and taxometric analyses of partial endoglucanase gene sequences of strains from this collection and from sequences previously deposited in DDBJ, EMBL, and GenBank databases showed that phylotype I strains formed a monophyletic cluster containing at least four distinct subgroups. Three of the subgroups (subgroups 1, 2, and 3) contained sequences from Philippine eggplant strains (this study) and the average number of nucleotide differences among these three subgroups was small $(<1 \%)$, indicating membership in only one sequevar. In contrast, subgroup 3, containing strains isolated from ginger and mioga, had $>1 \%$ difference in the average number of nucleotides compared with two of the other three subgroups, suggesting that they may belong to a different sequevar. Villa et al. (50) also found that some of these subgroup 3 strains had unique endoglucanase sequences

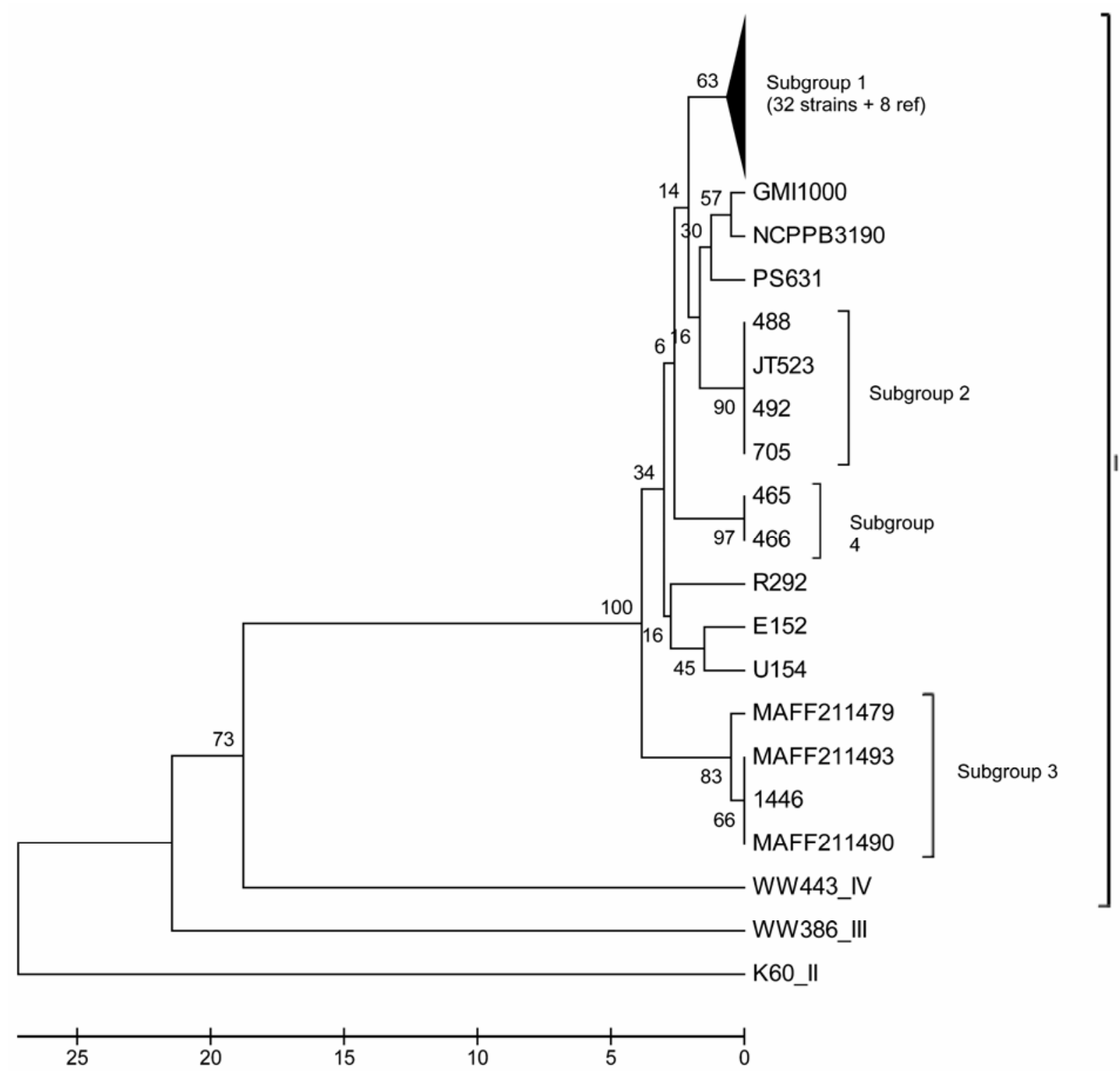

Fig. 3. Taxometric analysis of partial endoglucanase gene sequences showing the resolution of distinct subgroups of phylotype I Ralstonia solanacearum strains. The dendrogram was generated by MEGA (version 3.1) software, using the unweighted pair group method with arithmetic mean applied to the distance matrix of nucleotide differences. Numbers at branch points indicate percent bootstrap support for 1,000 iterations. Subgroup 1 contains 32 strains from our collection and eight reference strains. Roman numerals represent the phylotype. The scale bar represents the average number of nucleotide substitutions among subgroup members at each branch point. 
compared with the other strains in their monophyletic cluster and that they could be distinguished based on their host range. Within phylotype I, Fegan and Prior (15) have reported five different sequevars (sequence variants 12, 13, 14, 16, and 18). Strain GMI1000 ( $R$. solanacearum type strain) has been reported to belong to sequevar 12 (15). In our study using taxometric analysis, GMI1000 differed from strains in subgroups 1,2 , and 4 by 4.2 , 1.0 , and $5.7 \mathrm{nt}$, respectively, which leads us to hypothesize that the strains from this study could belong to sequevar 12 . However, in our phylogenetic analysis, GMI1000 formed its own subgroup, but with a weak bootstrap value, making its association with our strains uncertain. Although some partial endoglucanase sequences have been deposited in DDBJ, EMBL, and GenBank databases, with the exception of GMI1000, strains have not been assigned to specific sequevars. Therefore, with the current published data, we are unable to determine whether our Philippine strains belong to a new sequevar or are members of one of the five sequevars mentioned above.

In contrast to the limited amount of published data available to assess genetic diversity of bacterial plant pathogens using sequevar determination, rep-PCR with ERIC, REP, and BOXA1R primers has been used reliably in combination with computerassisted pattern analysis to characterize and assess genetic diversity in a wide range of pathogenic phytobacteria, including species of Xanthomonas (31-33,44), Pseudomonas (31), Clavibacter $(5,30)$, and Ralstonia $(17,24-26,28,45)$. Where sequevar analysis did not reveal any genetic diversity within our collection, ERICPCR defined eight band-based or four whole-pattern genotypes. Based on data from this study, although rep-PCR results are concordant with sequevar analyses, rep-PCR is more discriminating than sequevar analysis. However, the general concordance of the rep-PCR with sequevar data is not entirely clear at this time, because sequevar assignments and sequevar type strains are not widely available. In addition, rep-PCR and computer-assisted data analyses, although still time consuming, do not require sequencing and, therefore, are more accessible tools for researchers in developing countries trying to understand $R$. solanacearum diversity.

Very little research has been done to relate rep-PCR fingerprint profiles within the $R$. solanacearum species complex to geographical location. In this study, analysis of ERIC-PCR fingerprints revealed one predominant band-based genotype in each of the sampled provinces except Quezon (Table 2), and there was a significant association between strain genotype (band-based and whole-pattern) and province of origin. However, genotyping results from this study did not concur with biovar results, suggesting that the underlying genetics related to biovar classification were not captured. This might reflect the inadequacy of the distinction between biovar 3 and biovar 4, as suggested by Harris (19), who found that the distinction was not valid based upon extended phenotyping. Although, in our study, biovar was not concordant with genotype, Frey et al. (17) found that compiled ERIC-, BOX-, and REP-PCR profiles distinguished biovars 1 and 3 of race $1 R$. solanacearum strains isolated from the French West Indies at a similarity coefficient of $18 \%$. In addition, Smith et al.

TABLE 3. Average number of nucleotide differences in the partial endoglucanase gene sequences (643 nucleotides) within and between the four subgroups of phylotype I strains of Ralstonia solanacearum ${ }^{\text {a }}$

\begin{tabular}{lcccc}
\hline Subgroup $^{\mathrm{b}}$ & 1 & 2 & 3 & 4 \\
\hline $1(n=40)$ & $\mathbf{0 . 4 ( \mathbf { 0 . 2 } )}$ & $\ldots$ & $\ldots$ & $\ldots$ \\
$2(n=4)$ & $4.0(1.9)$ & $\mathbf{0 . 0 ( 0 . 0 )}$ & $\ldots$ & $\ldots$ \\
$3(n=4)$ & $7.8(2.7)$ & $5.8(2.3)$ & $\mathbf{0 . 5 ( \mathbf { 0 . 5 } )}$ & $\ldots$ \\
$4(n=2)$ & $5.2(2.2)$ & $3.2(1.7)$ & $7.0(2.4)$ & $\mathbf{0 . 0 ( \mathbf { 0 . 0 } )}$ \\
\hline
\end{tabular}

a Average number of nucleotide differences within a subgroup are represented in bold and standard error for each value is shown in brackets.

$\mathrm{b}$ Total number $(n)$ of strains analyzed in each subgroup.
(45) showed that rep-PCR (using ERIC and BOX primers) could be used to distinguish a race 3 biovar N2 strain from several race 3 biovar 2 strains isolated from potato in Kenya. Thus, compiling and analyses of rep-PCR fingerprint profiles using multiple primer sets (e.g., REP, BOX, and ERIC) may provide sufficiently discriminatory data that can be used to infer biovar type. Further studies using rep-PCR fingerprint profiles to assess the relationship of genotypes to location and aggressiveness also may be useful for the development of much-needed management practices and disease-resistant cultivars.

The genetic variation in $R$. solanacearum strains among provinces in the Philippines may provide a starting point to study pathogen-targeted management practices, including the possible development of genotype-specific resistant eggplant. Fine-scale genotypic studies of other bacterial groups have revealed that the distribution of specific genotypes in the environment can vary significantly. For example, culture-based studies of different Pseudomonas spp. have indicated that some genotypes are widely distributed (e.g., across continents) while others apparently are endemic to much smaller areas (e.g., $\left.<10 \mathrm{~km}^{2}\right)(8,33-35)$. Using RFLP-PCR analysis to compare the genetic diversity of strains of the bacterial blight pathogen of rice (Xanthomonas oryzae pv. oryzae) from Indonesia and the Philippines, George et al. (18) also found regional differentiation of the pathogen populations. However, the predominant strains in the collections from both countries were closely related. Adhikari et al. $(1,2)$ found high genetic diversity of the bacterial blight pathogen throughout Nepal and demonstrated regional differentiation of clusters of $X$. oryzae pv. oryzae in Asia along with the association of some pathotypes of $X$. oryzae pv. oryzae with single clusters. In contrast, Jaunet and Wang (26) could not relate genotype to geographical origin for a set of $R$. solanacearum strains isolated from tomato; however, they did suggest that a larger sample size may be needed. Jaunet and Wang (26) and Kumar et al. (28) had similar findings comparing strains from Taiwan and India, respectively. Because regional differences exist in plant-associated microbial populations, regional-scale breeding programs may improve efforts to develop resistant cultivars for the diverse genotypes of bacterial pathogens.

In this study, we were able to assess the genetic diversity of a group of $R$. solanacearum strains collected from five provinces of the Philippine island group of Luzon using the hierarchical classification scheme proposed by Fegan and Prior (15). Our data confirmed the species and phylotype scheme of the hierarchical classification; however, we were unable to confirm the sequevar scheme or fully understand its usefulness in the classification system. Because rep-PCR fingerprint profiles discriminate below the sequevar level, are easier to employ then gene sequencing (especially in developing countries), and can identify discrete polymorphisms within a sampled population, the sequevar scheme, at this time, may not be needed. Fegan and Prior (15) suggest that phylotypes and sequevars may be used to identify phenotypes in the future. However, this cannot be achieved until sequevar assignments to published strains are made available. With further studies using rep-PCR fingerprint profiles to assess the relationship of genotypes to location and virulence, the development of disease resistant cultivars and other management strategies may be better supported.

\section{ACKNOWLEDGMENTS}

This work was supported by the Integrated Pest Management Collaborative Research Support Program (IPM CRSP) funded by USAID Economic Growth, Agriculture, and Trade Bureau No. LAG-G-00-9300053-00, and by state and federal funds appropriated to the Ohio Agricultural Research and Development Center, The Ohio State University. We thank G. Tusiime and A. Saeb for providing excellent technical support, and S. Gordon and P. Paul for critical reviews of this manuscript. 


\section{LITERATURE CITED}

1. Adhikari, T. B., Mew, T. W., and Leach, J. E. 1999. Genotypic and pathotypic diversity in Xanthomonas oryzae pv. oryzae in Nepal. Phytopathology 89:687-694.

2. Adhikari, T. B., Vera Cruz, C. M., Zhang, Q., Nelson, R. J., Skinner, D. Z., Mew, T. W., and Leach, J. E. 1995. Genetic diversity of Xanthomonas oryzae pv. oryzae in Asia. Appl. Environ. Microbiol. 61:966-971.

3. Agricultural Biotechnology Support Project II (ABSP II). 2006. Fruit and Shoot Borer-Resistant Eggplant. Online publication fact sheet 20051100.

4. Altschul, S. F., Madden, T. L., Schaffer, A. A., Zhang, J., Zhang, Z., Miller, W., and Lipman, D. J. 1997. Gapped BLAST and PSI-BLAST: A new generation of protein database search programs. Nucleic Acid Res. 25:3389-3402.

5. Alvarez, A. M., Kaneshiro, W. S., and Vine, B. G. 2005. Diversity of Clavibacter michiganensis subsp. michiganensis populations in tomato seed: what is the significance? Acta Hortic. 695:205-214.

6. Buddenhagen, I., and Kelman, A. 1964. Biological and physiological aspects of bacterial wilt caused by Pseudomonas solanacearum. Annu. Rev. Phytopathol. 2:203-230.

7. Buddenhagen, I., Sequeira, L., and Kelman, A. 1962. Designation of races in Pseudomonas solanacearum. Phytopathology 52:726.

8. Cho, J.-C., and Tiedje, J. M. 2000. Biogeography and degree of endemicity of fluorescent Pseudomonas strains in soil. Appl. Environ. Microbiol. 66:5448-5456.

9. Cook, D., Barlow, E., and Sequeira, L. 1989. Genetic diversity of Pseudomonas solanacearum: Detection of restriction fragment polymorphisms with DNA probes that specify virulence and the hypersensitive response. Mol. Plant-Microbe Interact. 2:113-121.

10. Cook, D., and Sequeira, L. 1994. Strain differentiation of Pseudomonas solanacearum by molecular methods. Pages 77-93 in: Bacterial Wilt: The Disease and Its Causative Agent, Pseudomonas solanacearum. A. C. Hayward and G. L. Hartman, eds. CAB International, Wallingford, UK.

11. de Bruijn, F. J. 1992. Use of repetitive extragenic palindromic and enterobacterial repetitive intergenic consensus sequences and the polymerase chain reaction to fingerprint the genomes of Rhizobium meliloti isolates and other soil bacteria. Appl. Environ. Microbiol. 58:2180-2187.

12. Elphinstone, J. G. 2005. The current bacterial wilt situation: A global overview. Pages 9-28 in: Bacterial Wilt Disease and the Ralstonia solancearum Species Complex. C. Allen, P. Prior, and A. C. Hayward, eds. American Phytopathological Society, St. Paul, MN.

13. Ewing, B., and Green, P. 1998. Base-calling of automated sequencer traces using Phred. II. Error probabilities. Genome Res. 8:186-194.

14. Ewing, B., Hillier, L., Wendl, M. C., and Green, P. 1998. Base-calling of automated sequencer traces using phred. I. Accuracy assessment. Genome Res. 8:175-185.

15. Fegan, M., and Prior, P. 2005. How complex is the "Ralstonia solancearum species complex?" Pages 449-461 in: Bacterial Wilt Disease and the Ralstonia solancearum Species Complex. C. Allen, P. Prior, and A. C. Hayward, eds. American Phytopathological Society, St. Paul, MN.

16. Fegan, M., Taghavi, M., Sly, L. I., and Hayward, A. C. 1998. Phylogeny, diversity and molecular diagnostics of Ralstonia solanacearum. Pages 1933 in: Bacterial Wilt Disease: Molecular and Ecological Aspects. P. Prior, C. Allen, and J. Elphinstone, eds. Springer-Verlag, New York.

17. Frey, P., Smith, J. J, Albar, L., Prior, P., Saddler, G. S., Trigalet-Demery, D., and Trigalet, A. 1996. Bacteriocin typing of Burkholderia solanacearum race 1 of the French West Indies and correlation with genomic variation of the pathogen. Appl. Environ. Microbiol. 62:473-479.

18. George, M. L. C., Bustamam, M., Cruz, W. T., Leach, J. E., and Nelson, R. J. 1997. Movement of Xanthomonas oryzae pv. oryzae in Southeast Asia detected using PCR-based DNA fingerprinting. Phytopathology 87:302-309.

19. Harris, D. C. 1972. Intra-specific variation in Pseudomonas solanacearum. Pages 14-21 in: Proc. Third Int. Conf. Plant Pathogenic Bacteria. Centre for Agricultural Publishing and Documentation (Pudoc), Wageningen, The Netherlands.

20. Hayward, A. C. 1964. Characterization of Pseudomonas solanacearum. J. Appl. Bacteriol. 27:265-277.

21. Hayward, A. C. 1991. Biology and epidemiology of bacterial wilt caused by Pseudomonas solanacearum. Annu. Rev. Phytopathol. 29:65-87.

22. Hayward, A. C., El-Nashaar, H. M., Nydegger, U., and De Lindo, L. 1990. Variation in nitrate metabolism in biovars of Pseudomonas solanacearum. J. Appl. Bacteriol. 69:269-280.

23. He, L. Y., Sequeira, L., and Kelman, A. 1983. Characteristics of strains of Pseudomonas solanacearum. Plant Dis. 67:1357-1361.

24. Horita, M., and Tsuchiya, K. 2001. Genetic diversity of Japanese strains of Ralstonia solanacearum. Phytopathology 91:399-407.

25. Horita, M., Tsuchiya, K., and Ooshiro, A. 2005. Characteristics of Ralstonia solanacearum Biovar N2 strains in Asia. J. Phytopathol. 153:209213.
26. Jaunet, T. X., and Wang, J. 1999. Variation in genotype and aggressiveness of Ralstonia solanacearum race 1 isolated from Taiwan. Phytopathology 89:320-327.

27. Kelman, A. 1954. The relationship of pathogenicity in Pseudomonas solanacearum to colony appearance on a tetrazolium medium. Phytopathology 44:693-695.

28. Kumar, A., Sarma, Y. R., and Anandaraj, M. 2004. Evaluation of genetic diversity of Ralstonia solanacearum causing bacterial wilt of ginger using REP-PCR and PCR-RFLP. Curr. Sci. 87:1555-1561.

29. Kumar, S., Tamura, K., and Nei, M. 2004. MEGA3: Integrated software for molecular evolutionary genetics analysis and sequence alignment. Brief. Bioinf. 5:150-163.

30. Louws, F. J., Bell, J., Medina-Mora, C. M., Smart, C. D., Opgenorth, D., Ishimaru, C. A., Hausbeck, M. K., de Bruijn, F. J., and Fulbright, D. W. 1998. rep-PCR-mediated genomic fingerprinting: A rapid and effective method to identify Clavibacter michiganensis. Phytopathology 88:862868.

31. Louws, F. J., Fulbright, D. W., and de Bruijn, F. J. 1994. Specific genomic fingerprints of phytopathogenic Xanthomonas and Pseudomonas pathovars and strains generated with repetitive sequences and PCR. Appl. Environ. Microbiol. 60:2286-2295.

32. Louws, F. J., Fulbright, D. W., Stephens, C. T., and de Bruijn, F. J. 1995. Differentiation of genomic structure by rep-PCR fingerprinting to rapidly classify Xanthomonas campestris pv. vesicatoria. Phytopathology 85:528536.

33. Mahuka, G. S., Jara, C., Henriquez, M. A., Castellanos, G., and Cuasquer, J. 2006. Genotypic characterization of the common bean bacterial blight pathogens, Xanthomonas axonopodis pv. phaseoli and Xanthomonas axonopodis pv. phaseoli var. fuscans by rep-PCR and PCR-RFLP of the ribosomal Genes. J. Phytopathol. 154:35-44.

34. McSpadden Gardener, B., Gutierrez, L. J., Joshi, R., Edema, R., and Lutton, E. 2005. Distribution and biocontrol potential of phlD ${ }^{+}$Pseudomonads in corn and soybean fields. Phytopathology 95:715-724.

35. McSpadden Gardener, B., Schroeder, K., Kalloger, S., Raaijmakers, J., Thomashow, L., and Weller, D. 2000. Genotypic and phenotypic diversity of phlD-containing Pseudomonas spp. isolated from the rhizosphere of wheat. Appl. Environ. Microbiol. 66:1939-1946.

36. Miller, S. A., Rezaul Karim, A. M. N., Baltazar, A. M., Rajotte, E. G., and Norton, G. W. 2005. Developing IPM packages in Asia. Pages 27-50 in: Globalizing Integrated Pest Management: A Participatory Research Process. G. W. Norton, E. A. Heinrichs, G. C. Luther, and M. E. Irwin, eds. Blackwell Publishing, IA.

37. Opina, N, Tavner, F., Hollway, G., Wang, J. F., Li, T. H., Maghirang, R., Fegan, M., Hayward, A.C., Krishnapillai, V., Hong, W. F., Holloway, B. W., and Timmins, J. 1997. A novel method for development of species and strain-specific DNA probes and PCR primers for identifying Burkholderia solancearum (formerly Pseudomonas solancearum). Asia Pac. J. Mol. Biol. Biotechnol. 5:19-30.

38. Opina, N. L., and Miller, S. A. 2005. Evaluation of immunoassays for detection of Ralstonia solanacearum, causal agent of bacterial wilt of tomato and eggplant in the Philippines. Acta Hortic. 695:353-356.

39. Pegg, K., and Moffett, M. 1971. Host range of the ginger strain of Pseudomonas solancearum in Queensland. Aust. J. Exp. Agric. Anim. Husb. 11:696-698.

40. Poussier, S., Prior, P., Luisetti, J., Hayward, C., and Fegan, M. 2000. Partial sequencing of the $h r p B$ gene and the endoglucanase genes confirms and expands the known diversity within the Ralstonia solanacearum species complex. Syst. Appl. Microbiol. 23:479-486.

41. Poussier, S., Trigalet-Demery, D., Vandewalle, P., Goffinet, B., Luisetti, J., and Trigalet, A. 2000. Genetic diversity of Ralstonia solanacearum as assessed by PCR-RFLP of the hrp gene region, AFLP and 16S rRNA sequence analysis, and identification of an African subdivision. Microbiology 146:1679-1692.

42. Prior, P., and Fegan, M. 2005. Recent developments in the phylogeny and classification of Ralstonia solanacearum. Acta Hortic. 695:127-136.

43. Rademaker, J. L. W., Louws, F. J., Rossbach, U., and de Bruijn, F. J. 1999. Computer assisted pattern analysis of molecular fingerprints and data base construction. Pages 1-33 in: Molecular Microbial Ecology Manual. A. D. L. Akkermans, J. D. van Elsas, and F. J. de Bruijn, eds. Kluwer Academic Publishers, Dordrecht, The Netherlands.

44. Sahin, F., Abbassi, P. A., Lewis Ivey, M. L., Zhang, J., and Miller, S. A. 2003. Diversity among strains of Xanthomonas campestris pv. vitians from lettuce. Phytopathology 93:64-70.

45. Smith, J. J., Offord, L. C., Holderness, M., and Saddler, G. S. 1995. Genetic diversity of Burkholderia solanacearum (synonym Pseudomonas solanacearum) race 3 in Kenya. Appl. Environ. Microbiol. 61:4263-4268.

46. Taghavi, M., Hayward, C., Sly, L., and Fegan, M. 1996. Analysis of the phylogenetic relationships of strains of Burkholderia solanacearum, Pseudomonas syzygii, and the blood disease bacterium of banana based on 16S rRNA gene sequences. Int. J. Syst. Bacteriol. 46:10-15. 
47. Verma, S. K., Gupta, N. N., and Phogat, K. P. S. 1997. Studies on the interaction between root knot nematodes, Meloidogyne spp., fungi, Fusarium oxysporum and $F$. solani and the bacterium, Pseudomonas solanacearum (Ralstonia solanancearum) on brinjal, Solanum melongena L. under valley condition of Garwal hills. Prog. Hortic. 29:188-193.

48. Versalovic, J., Koeuth, T., and Lupski, J. R. 1991. Distribution of repetitive DNA sequences in eubacteria and application to fingerprinting of bacterial genomes. Nucleic Acids Res. 19:6823-6831.
49. Versalovic, J., Schneider, M., de Bruijn, F. J., and Lupski, J. R. 1994. Genomic fingerprinting of bacteria using repetitive sequence-based polymerase chain reaction. Methods Mol. Cell. Biol. 5:25-40.

50. Villa, J. E., Tsuchiya, K., Horita, M., Natural, M., Opina, N., and Hyakumachi, M. 2005. Phylogenetic relationships of Ralstonia solanacearum species complex strains from Asia and other continents based on $16 \mathrm{~S}$ rDNA, endoglucanase, and $h r p B$ gene sequences. J. Gen. Plant Pathol. 71:39-46. 